Revista Brasileira de Agricultura Irrigada v.13, no.3, p.3477 - 3486, 2019

ISSN 1982-7679 (On-line)

Fortaleza, CE, INOVAGRI - http://www.inovagri.org.br

DOI: $10.7127 /$ rbai.v13n301082

Protocolo 1082.19 - 12/04/2019 Aprovado em 23/06/2019

\title{
MORFOFISIOLOGIA E QUALIDADE DE PORTA-ENXERTO DE CAJUEIRO SOB PERÓXIDO DE HIDROGÊNIO E ESTRESSE SALINO
}

\author{
Leandro de Pádua Souza ${ }^{1}$, Reginaldo Gomes Nobre ${ }^{2}$, Reynaldo Teodoro Fatima ${ }^{3}$, Thiago Alves \\ Pimenta $^{4}$, Genilson Lima Diniz ${ }^{5}$, Joicy Lima Barbosa ${ }^{6}$
}

\begin{abstract}
RESUMO
A menor qualidade de água usada na irrigação na produção agrícola nas regiões semiáridas, requer o desenvolvimento de tecnologias e/ou estratégias que minimizem o efeito deletério da salinidade presente na água de irrigação. Desta forma objetivou-se avaliar a influência de diferentes concentrações de peróxido de hidrogénio via tratamento de sementes sobre as respostas fisiológicas, de crescimento e qualidade de porta-enxerto de cajueiro Embrapa 51 irrigado com águas de distintas salinidades. $\mathrm{O}$ ensaio foi desenvolvido em ambiente protegido da Universidade Federal de Campina Grande do Centro de Ciências e Tecnologia Agroalimentar, campus Pombal - PB, utilizando-se delineamento de blocos casualizados, em esquema fatorial 5 x 4, com quatro repetições e duas plantas por parcela, cujos tratamentos consistiram em diferentes níveis de condutividades elétricas da água de irrigação - $\mathrm{CEa}\left(0,3 ; 1,1 ; 1,9 ; 2,7\right.$ e $\left.3,5 \mathrm{dS} \mathrm{m}^{-1}\right)$ associados às concentrações de peróxido de hidrogênio - $\mathrm{H}_{2} \mathrm{O}_{2}(0 ; 10 ; 20$ e $30 \mu \mathrm{M})$. As diferentes concentrações de $\mathrm{H}_{2} \mathrm{O}_{2}$ foram obtidas a partir da diluição, em água destilada, da solução de peróxido de hidrogénio $1 \mathrm{M}$. As trocas gasosas, formação de massa fresca e seca e a qualidade de porta-enxerto de cajueiro é reduzido pelo aumento da salinidade da água de irrigação, no entanto a rega com água de $\mathrm{CEa} 1,68 \mathrm{dS} \mathrm{m}^{-1}$, promove reduções aceitáveis de $10 \%$ na morfofisiologia do cajueiro "Embrapa 51". De forma geral, a uso das concentrações de $10 \%$ de peroxido de hidrogênio proporciona os maiores acúmulos de fitomassa e qualidade dos porta-enxertos de cajueiro. Concentrações de peróxido de hidrogênio de $10 \%$ proporcionou maior tolerâncias nas variáveis estudadas.
\end{abstract}

Palavras-chave: Anacardium occidentale L., produção de mudas, salinidade.

\section{MORPHOPHYSIOLOGY AND QUALITY OF CASHEW ROOTSTOCK UNDER HYDROGEN PEROXIDE AND SALINE STRESS}

\footnotetext{
${ }^{1}$ Doutorando em Engenharia Agrícola, Universidade Federal de Campina Grande, Campina Grande - Paraíba, Brasil, Email:engenheiropadua@hotmail.com

${ }^{2}$ Professor Adjunto, UFERSA / Campus Caraúbas - RN, Brasil, rgomesnobre@yahoo.com.br

${ }^{3}$ Mestrando em Agronomia, UFPB - CCA, Areia, Paraíba, Brasil, e-mail: reynaldo.t16@ hotmail.com

${ }^{4}$ Doutorando em proteção de plantas, Universidade Federal de Alagoas, Maceió, Alagoas, Brasil, e-mail: tpimenta62@hotmail.com

${ }^{5}$ Mestrando em horticultura Tropical, Universidade Federal de Campina Grande, Pombal, Paraíba, Brasil, genilsondiniz02@hotmail.com

${ }^{6}$ Mestranda em agronomia-produção vegetal, Universidade Federal de Alagoas, Maceió, Alagoas, Brasil, e-mail: joicy.barbosa0@hotmail.com
} 


\begin{abstract}
With the scarcity of good quality water, it is necessary to use irrigation as an alternative for agricultural production in semi-arid regions. However, its use depends on the development of technologies that minimize the deleterious effect of salinity present in irrigation water. Thus the objective of this study was to evaluate the influence of different concentrations of hydrogen peroxide via seed treatment on the physiological, growth and quality responses of Embrapa 51 cashew rootstock irrigated with waters of different salinities. The experiment was carried out in a protected environment of the Federal University of Campina Grande of the Agro-Food Science and Technology Center, Pombal campus, where a randomized block design was used in a $5 \times 4$ factorial scheme with four replications and two plants, with water salinity of $0.3,1.1,1.9,2.7$ and $3.5 \mathrm{dS} \mathrm{m}^{-1}$ associated with the concentrations of hydrogen peroxide $\mathrm{H}_{2} \mathrm{O}_{2}(0 ; 10 ; 20$ e $30 \mu \mathrm{M})$. The different concentrations of $\mathrm{H}_{2} \mathrm{O}_{2}$ were obtained from the dilution in distilled water of the $1 \mathrm{M}$ hydrogen peroxide solution.Gas exchange, fresh and dry mass formation and quality of cashew rootstock are reduced by increasing salinity of irrigation water, however irrigation with water of $1.68 \mathrm{dS} \mathrm{m}^{-1}$, promotes acceptable reductions of $10 \%$ in the cashew morphology of "Embrapa 51". In general, the use of the $10 \%$ concentrations of hydrogen peroxide provides the greatest accumulations of phytomass and quality of cashew rootstocks.
\end{abstract}

Keywords: Anacardium occidentale L., seedling production; salinity.

\section{INTRODUÇÃO}

O cajueiro (Anacardium occidentale L.), pertencente à família Anacardiaceae, é uma das principais fruteiras nativas de importância socioeconómica explorada na região Nordeste do Brasil, com uma área colhida de 585.966 hectares e uma produção de 103.848 toneladas (ALMEIDA et al., 2017).

Estas regiões são caracterizadas por reduzidas pluviosidades e altas taxas de evaporação ocasionando naturalmente, um déficit hídrico que limita o crescimento, o desenvolvimento e a produção das culturas sob condições naturais, ou seja, a exploração agrícola racional só se torna possível a partir do uso da rega, entretanto, as águas disponíveis para irrigação nestas regiões nem sempre são de boa qualidade fazendo com que o uso de águas salinas se torne uma realidade, caracterizando um problema que atinge a economia, a sociedade e o ambiente (MEDEIROS et al., 2012; NASCIMENTO et al., 2017).

Uma das alternativas que pode minimizar o efeito do estresse salino nas plantas é o processo de aclimatação a determinadas condições de estresse e constitui numa alternativa para aumentar a capacidade de sobrevivência das plantas a condições adversas. A aclimatação é um processo no qual a exposição prévia de um indivíduo a um determinado tipo de estresse provoca mudanças metabólicas que são responsáveis pelo aumento de sua tolerância a uma posterior exposição ao estresse (GONDIM et al., 2011), sendo o peróxido de hidrogênio $\left(\mathrm{H}_{2} \mathrm{O}_{2}\right)$ uma das alternativas promissoras no retardamento dos efeitos do estresse salino nas plantas (SILVA et al., 2016).

Diante disto, objetivou-se com o trabalho avaliar a influência de diferentes concentrações de peróxido de hidrogênio via tratamento de sementes nas respostas fisiológicas, de crescimento e qualidade de porta-enxerto de cajueiro Embrapa 51 irrigado com águas salinas.

\section{MATERIAL E MÉTODOS}

O experimento foi conduzido de junho a setembro de 2017, em condições de ambiente protegido (casa de vegetação) no Centro de Ciências e Tecnologia Agroalimentar da Universidade Federal de Campina Grande (CCTA/UFCG), Campus Pombal-PB, 6048'16" $\mathrm{S}, 37^{\circ} 49^{\prime} 15^{\prime \prime} \mathrm{O}$ e altitude média de $144 \mathrm{~m}$.

Adotou-se o delineamento de blocos casualizados, em esquema fatorial $5 \times 4$, com quatro repetições e duas plantas por parcela, para reduzir as variações provenientes do manejo das mudas, cujos tratamentos consistiram em diferentes níveis de condutividades elétricas da água de irrigação $\mathrm{CEa}\left(0,3 ; 1,1 ; 1,9 ; 2,7\right.$ e $\left.3,5 \mathrm{dS} \mathrm{m}^{-1}\right)$ associados 


\section{MORFOFISIOLOGIA E QUALIDADE DE PORTA-ENXERTO DE CAJUEIRO SOB PERÓXIDO} DE HIDROGÊNIO E ESTRESSE SALINO

a concentrações de peróxido de hidrogénio $\mathrm{H}_{2} \mathrm{O}_{2}$ a $0 ; 10 ; 20$ e $30 \mu \mathrm{M}$.

Os níveis salinos foram baseados em Sousa et al. (2011), que observaram uma inibição acentuada no crescimento do cajueiro a partir do nível salino de $1,58 \mathrm{dS} \mathrm{m}^{-1}$. As águas de diferentes salinidades foram obtidas a partir da água de abastecimento $\left(0,3 \mathrm{dS} \mathrm{m}^{-1}\right)$ mediante a adição de cloreto de sódio $(\mathrm{NaCl})$, de cálcio $\left(\mathrm{CaCl}_{2} .2 \mathrm{H}_{2} \mathrm{O}\right)$ e de magnésio $\left(\mathrm{MgCl}_{2} .6 \mathrm{H}_{2} \mathrm{O}\right)$, na proporção de 7:2:1, relação esta predominante nas principais fontes de água disponíveis para irrigação no Nordeste brasileiro (MEDEIROS, 1992), obedecendo-se à relação entre CEa e a concentração dos sais $\left(\mathrm{mg} \mathrm{L}^{-1}=640 \times \mathrm{CEa}\right)$ (RHOADES et al., 2000). As diferentes concentrações de $\mathrm{H}_{2} \mathrm{O}_{2}$ foram obtidas a partir da diluição, em água destilada, da solução de peróxido de hidrogénio $1 \mathrm{M}$.

Para os tratamentos com $\mathrm{H}_{2} \mathrm{O}_{2}$ utilizaram-se copos envolvidos com papel alumínio, onde 20 sementes foram imersas em $500 \mathrm{~mL}$ de solução de cada concentração, durante 24 horas.
Como material vegetal utilizou-se o clone de cajueiro anão precoce Embrapa 51 por ser um dos mais usados como porta-enxerto por viveiristas do nordeste brasileiro por apresentar uma maior taxa de germinação $(88,26 \%)$ (SERRANO et al., 2013). As sementes, provenientes de uma área de exploração comercial localizado no município de Severiano Melo - RN, foram selecionadas previamente conforme tamanho e sanidade.

Para a obtenção dos portas-enxerto foram utilizadas sacolas plásticas, com $1250 \mathrm{~mL}$ de capacidade, perfuradas na parte inferior para permitir a livre drenagem da água.

O substrato usado foi composto de solo + Areia + Estrume bovino curtido, respectivamente na proporção de $2: 1: 1$; o solo foi coletado na camada de $0-20 \mathrm{~cm}$ no Lote 14 , setor I, do Perímetro Irrigado das Várzeas de Sousa-PB, cujas características físicas e químicas (Tabela 1), foram obtidas conforme Claessen (1997) e analisadas no Laboratório de Irrigação e Salinidade UFCG/Campina Grande-PB.

Tabela 1. Características físicas e químicas do substrato utilizado no ensaio.

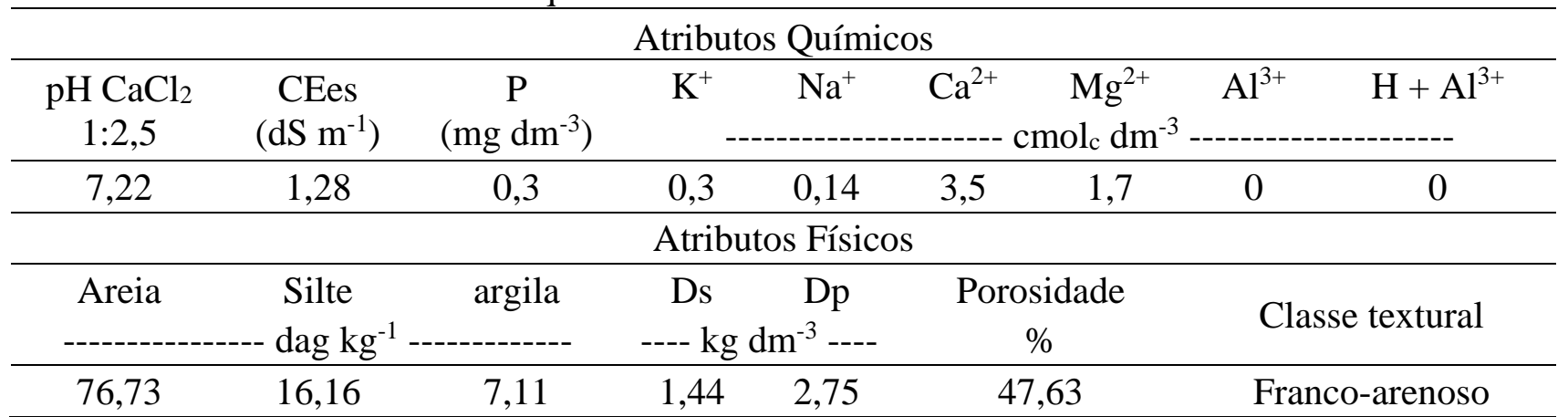

$\mathrm{pH}=\mathrm{pH}$ em CaCl 2 1:2,5 CEes $=$ Condutividade elétrica do extrato de saturação do substrato a $25^{\circ} \mathrm{C}$

As sacolas foram acomodadas em bancadas metálicas (cantoneiras), a uma altura de $0,80 \mathrm{~m}$ da superficie, usando uma castanha por sacola, cujo substrato se encontrava à capacidade de campo com água de $0,3 \mathrm{dS} \mathrm{m}^{-1}$, inserindo-se a castanha na posição vertical com a base (ponto de inserção da castanha ao pedúnculo) voltada para cima, à profundidade de aproximadamente $1 \mathrm{~cm}$, conforme recomendações da EMBRAPA- CNPAT (CAVALCANTI JÚNIOR; CHAVES, 2001). As plântulas emergiram aos 10 dias após a sementeira (DAS), tendo-se iniciado a aplicação dos diferentes níveis salinos aos 25 dias após a emergência (DAE), com regas diárias no início da manhã e final da tarde de forma manual usando uma proveta graduada. As regas foram feitas baseadas no processo de lisimetria de drenagem (utilizando 20 sacolas com um coletor em cada), com registo diário do volume retido nas sacolas, determinado pela diferença entre o volume aplicado e o drenado (SOUZA et al., 2016). Foi aplicado a cada 10 dias, uma fração de lixiviação de 0,15 com base no volume aplicado neste período, com o propósito de reduzir a acumulação excessiva de 
sais no substrato. Aos 80 DAE foram realizadas medições da taxa de transpiração $(E) \mathrm{e}$ condutância estomática $(g s)$ em folhas completamente desenvolvidas, utilizando-se um analisador de gás no infravermelho IRGA (LCI System, ADC, Hoddesdom). A produção de massa fresca e seca de porta-enxerto foi avaliada também aos 80 DAE, considerado como tempo médio necessário para produção de porta-enxerto de cajueiro (SERRANO et al., 2013). As plantas foram colhidas rente ao solo, em seguida realizou-se a lavagem das raízes para eliminar o solo aderido e dividiu-se cada

$$
\mathrm{IQD}=\frac{(\mathrm{MST})}{(\mathrm{AP} / \mathrm{DC})+(\mathrm{MSPA} / \mathrm{MSR})}
$$

Em que: IQD = índice de qualidade de Dickson; $\mathrm{AP}=$ altura de planta $(\mathrm{cm})$ da superfície do solo até ponto de inserção do meristema apical;

$\mathrm{DC}=$ diâmetro do caule $(\mathrm{mm})$ a $5 \mathrm{~cm}$ do colo da planta;

MST = massa seca total de planta (g);

MSPA = massa seca da parte aérea de planta (g); obtida a partir do somatório MSF;

MSC e MSR = massa seca de raiz de planta $(\mathrm{g})$.

Os dados obtidos foram submetidos à análise de variância, pelo teste $\mathrm{F}$ em nível de 0,05 de probabilidade e nos casos de significância, realizou-se análise de regressão utilizando do software estatístico SISVAR (FERREIRA, 2011). planta em folha, caule e raiz, posteriormente, o material foi acondicionado em sacos de papel e pesado para determinação da massa fresca das folhas (MFF) e caule (MFC), sendo depois colocadas em estufa de circulação de ar à $65^{\circ} \mathrm{C}$ até obtenção do peso constante para determinação da massa seca das folhas (MSF), de caule (MSC), de raiz (MSR) e massa seca total (MST). A qualidade do porta-enxerto foi também determinada aos 80 DAE através do índice de qualidade de Dickson (IQD) para mudas, por meio da fórmula de Dickson et al. (1960), conforme:

\section{RESULTADOS E DISCUSSÃO}

Verifica-se, com base no resumo da análise de variância (Tabela 2), que não houve efeito significativo $(p>0,05)$ do fator salinidade da água de irrigação e concentrações de $\mathrm{H}_{2} \mathrm{O}_{2}$ sobre condutância estomática e taxa de transpiração. No entanto nota-se efeito significativo da salinidade $(\mathrm{p}<0,01)$ de forma isolada para massa fresca de folha do portaenxerto de cajueiro Embrapa 51. Já para a massa fresca e seca do caule e seca das folhas, observou-se interação significativa $(\mathrm{p}<0,01)$ entre os fatores salinidade da água de irrigação e concentrações de peróxido de hidrogênio, aos 80 DAE (Tabela 2).

Tabela 2. Análise de variância para condutância estomática $\left(\mathrm{g}_{\mathrm{s}}\right)$, taxa de transpiração $(\mathrm{E})$, massa fresca da folha (MFF), do caule (MFC), seca das folhas (MSF) e do caule (MSC) de porta-enxerto de cajueiro Embrapa 51, provenientes de sementes tratadas com diferentes concentrações de $\mathrm{H}_{2} \mathrm{O}_{2}$ e rega com águas salinas, aos 80 dias após emergência.

\begin{tabular}{lccccccc}
\hline \multirow{2}{*}{ Fonte de variação } & \multirow{2}{*}{$\mathrm{GL}$} & \multicolumn{7}{c}{ Quadrado Médio } \\
\cline { 3 - 7 } & & $\mathrm{g}_{\mathrm{s}}$ & $\mathrm{E}$ & $\mathrm{MFF}$ & $\mathrm{MFC}$ & $\mathrm{MSF}$ & $\mathrm{MSC}$ \\
\hline Níveis salinos (S) & 4 & $0,0001^{\mathrm{ns}}$ & $0,13^{\mathrm{ns}}$ & $17,70^{* *}$ & $7,08^{* *}$ & $1,72^{* *}$ & $0,61^{* *}$ \\
$\quad$ Reg. Linear & 1 & $0,00003^{\mathrm{ns}}$ & $0,06^{\mathrm{ns}}$ & $54,73^{* *}$ & $25,65^{* *}$ & $5,65^{* *}$ & $2,21^{* *}$ \\
$\quad$ Reg. Quadrática & 1 & $0,0004^{\mathrm{ns}}$ & $0,33^{\mathrm{ns}}$ & $13,76^{* *}$ & $1,50^{\mathrm{ns}}$ & $0,90^{* *}$ & $0,22^{* *}$ \\
Peróxido de hidrogênio & 3 & $0,0005^{\mathrm{ns}}$ & $0,33^{\mathrm{ns}}$ & $1,02^{\mathrm{ns}}$ & $1,10^{\mathrm{ns}}$ & $0,17^{* *}$ & $0,30^{* *}$ \\
$\left(\mathrm{H}_{2} \mathrm{O}_{2}\right)$ & 1 & $0,0004^{\mathrm{ns}}$ & $0,14^{\mathrm{ns}}$ & $0,10^{\mathrm{ns}}$ & $1,04^{\mathrm{ns}}$ & $0,15^{* *}$ & $0,87^{* *}$ \\
$\quad$ Reg. Linear & 1 & $0,0001^{\mathrm{ns}}$ & $0,15^{\mathrm{ns}}$ & $0,003^{\mathrm{ns}}$ & $0,27^{\mathrm{ns}}$ & $0,15^{* *}$ & $0,01^{\mathrm{ns}}$ \\
$\quad$ Reg. Quadrática & 12 & $0,0001^{\mathrm{ns}}$ & $0,12^{\mathrm{ns}}$ & $7,23^{\mathrm{ns}}$ & $3,22^{* *}$ & $0,56^{* *}$ & $1,42^{* *}$ \\
Interação $\left(\mathrm{S} \times \mathrm{H}_{2} \mathrm{O}_{2}\right)$ & 3 & $0,0002^{\mathrm{ns}}$ & $0,12^{\mathrm{ns}}$ & $1,60^{\mathrm{ns}}$ & $0,44^{\mathrm{ns}}$ & $0,007^{\mathrm{ns}}$ & $0,01^{\mathrm{ns}}$ \\
Bloco & & 20,21 & 18,45 & 21,48 & 17,22 & 5,35 & 4,34 \\
$\mathrm{CV}(\%)$ & & & & & & & \\
\hline
\end{tabular}

ns, $* *, *$ respectivamente não significativos, significativo a $\mathrm{p}<0,01$ e p $<0,05$ 


\section{MORFOFISIOLOGIA E QUALIDADE DE PORTA-ENXERTO DE CAJUEIRO SOB PERÓXIDO} DE HIDROGÊNIO E ESTRESSE SALINO

De acordo com a Figura 1A, para massa fresca de folha (MFF) aos 80 DAE, constata-se melhor ajuste dos dados em regressão quadrática, pelo aumento da condutividade elétrica da água de rega, cujo maior valor, correspondente $5,32 \mathrm{~g}$ por planta, foi obtido com utilização de CEa $1,0 \mathrm{dS} \mathrm{m}^{-1}$ e o valor mínimo de $2,82 \mathrm{~g}$ por planta quando submetidas a condutividade de $3,5 \mathrm{dS} \mathrm{m}^{-1}$. A redução na fitomassa da folha foi decorrente do menor número de folhas das plantas, sendo tais efeitos da salinidade já registrados por Souza et al. (2016). O aumento da CEa causou diminuição na acumulação de massa fresca, devido aos efeitos do aumento de sais solúveis no solo, que promovem a redução do potencial osmótico do solo e consequente maior dificuldade para as plantas absorverem água em quantidades satisfatórias ao contínuo crescimento, ocorrendo assim alterações morfológicas e anatómicas, como redução do tamanho das folhas, reduzindo a produção de biomassa nas plantas cultivadas em condições de estresse salino (OLIVEIRA et al., 2013).
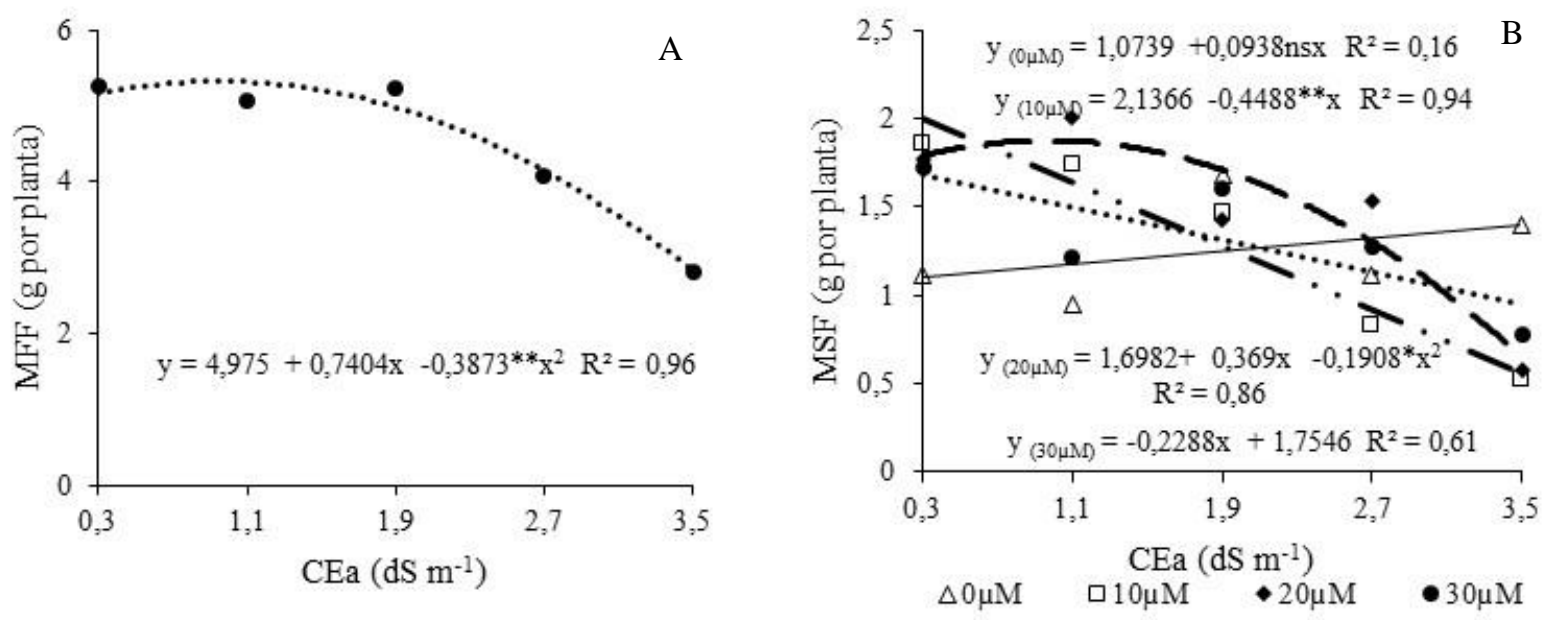

Figura 1. Massa fresca da folha (MFF) de porta-enxerto de cajueiro Embrapa 51, em função da salinidade da água de rega - CEa (A) e massa seca da folha (MSF) da folha em função da interação entre os níveis de CEa e diferentes concentrações de $\mathrm{H}_{2} \mathrm{O}_{2}$ (B) aos 80 dias após emergência.

A MSF das plantas (Figura 1B) submetidas a 10 e $20 \mu \mathrm{M}$ de peróxido apresentou decréscimos lineares de 67,21 e $41,72 \%$ com o aumento da CEa de 0,3 a $3,5 \mathrm{dS} \mathrm{m}^{-1}$ respectivamente. Nota-se de acordo com a equação de regressão resposta quadrática, onde o maior valor foi de $1,87 \mathrm{~g}$ por planta, foi encontrado na concentração de $20 \mu \mathrm{M}$ de $\mathrm{H}_{2} \mathrm{O}_{2}$ nas plantas regadas com CEa de $1,0 \mathrm{dS} \mathrm{m}^{-1}$. Este efeito pode estar associado ao estresse oxidativo, ocasionando a peroxidação lipídica, danos nas membranas celulares, degradação de proteínas, quebra da dupla fita do DNA e, ainda, a morte celular, reduzindo a produção de biomassa das plantas (NGUYEN et al., 2009).

Observa-se na Figura 2A que o uso da concentração de $10 \mu \mathrm{M}$ de $\mathrm{H}_{2} \mathrm{O}_{2}$ causou redução linear na MFC com o aumento da condutividade da água de rega, onde as plantas que receberam a maior $\mathrm{CEa}\left(3,5 \mathrm{dS} \mathrm{\textrm {m } ^ { - 1 } )}\right.$ sofreram decréscimos de $29,61 \%$ quando comparadas com as plantas que receberam a menor salinidade $\left(0,3 \mathrm{dS} \mathrm{m}^{-1}\right)$. Gondim et al. (2010), com plantas de milho provenientes de sementes pré-tratadas com $\mathrm{H}_{2} \mathrm{O}_{2}$ e submetidas à salinidade, e Wahid et al. (2007), trabalhando com plantas de trigo também oriundas de sementes pré-tradadas, observaram que o prétratamento conferiu tolerância à salinidade nas plantas. Nota-se ainda que as concentrações de 20 e $30 \mu \mathrm{M}$ de $\mathrm{H}_{2} \mathrm{O}_{2}$ promoveram efeito quadrático sobre a MFC das plantas, onde os maiores valores de 5,20 e 6,51 g por planta foram obtidos nos níveis de CEa de 1,4 e 0,3 dS $\mathrm{m}^{-1}$ nas respectivas doses de $\mathrm{H}_{2} \mathrm{O}_{2}$ (Figura $2 \mathrm{~A}$ ). Este efeito pode estar associado ao aumento do peróxido de hidrogênio até $20 \mu \mathrm{M}$ promovendo aumento na tolerância ativando o sistema de 
defesa das plantas ao estresse salino, incluindo ativação de sistema oxidativo enzimático, acumulação de solutos orgânicos, redução na

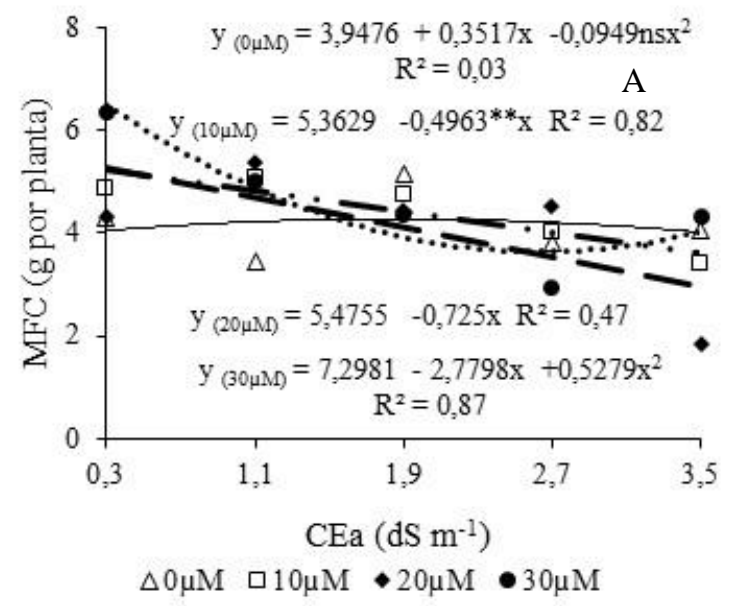

peroxidação de lípidos e dano membranar (GONDIM et al., 2011; CARVALHO et al., 2011).

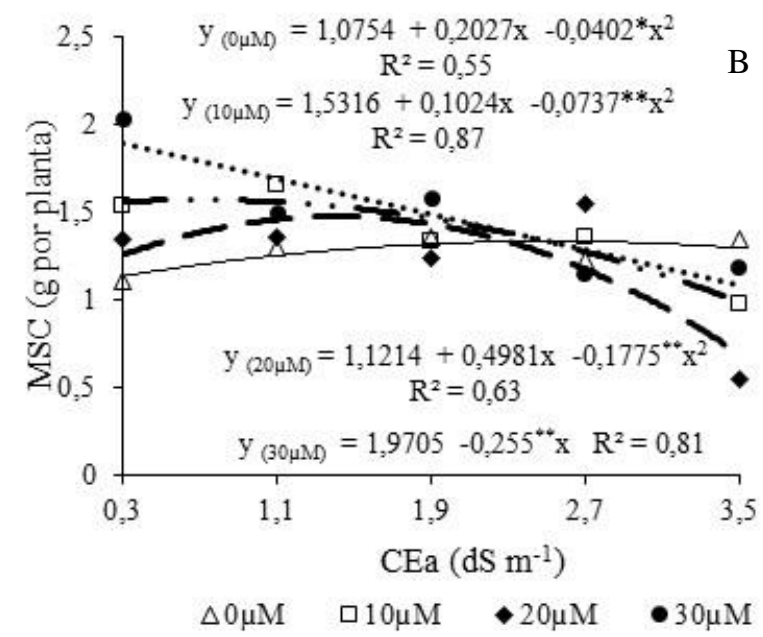

Figura 2. Massa fresca - MFC (A) e seca - MSC (B) do caule de porta-enxerto de cajueiro Embrapa 51, em função da interação entre os níveis de salinidade da água CEa e diferentes concentrações de $\mathrm{H}_{2} \mathrm{O}_{2}$, aos 80 dias após emergência.

$\mathrm{O}$ aumento das concentrações de $\mathrm{H}_{2} \mathrm{O}_{2}$ proporcionaram efeito quadrático sobre a MSC de porta-enxerto de cajueiro Embrapa 51 (Figura 2B) onde, nas concentrações de 0; $10 \mathrm{e}$ $20 \mu \mathrm{M}$ de $\mathrm{H}_{2} \mathrm{O}_{2}$ os maiores valores de MSC encontrados foram de 1,33, 1,56 e 1,47 g por planta nas CEa de 2,5; 0,7 e 1,4 (dS m-1), respectivamente. Associado a isso pode dizer que o incremento na dose de peróxido até $10 \%$ promoveu aumento na tolerância, fato esse explicado possivelmente devido aos mecanismos de defesa desenvolvidos pela própria planta induzindo o sistema de defesa de enzimas antioxidativas, minimizando os efeitos deletérios da salinidade (CARVALHO et al., 2011; SILVA et al., 2016). No entanto observou-se que a concentração de $30 \mu \mathrm{M}$ de $\mathrm{H}_{2} \mathrm{O}_{2}$ resultou em decréscimo nesta variável associado com o aumento da salinidade da água de rega proporcionando uma diminuição de $41,42 \%(0,81 \mathrm{~g})$ nas plantas submetidas ao maior nível de salinidade $\left(3,5 \mathrm{dS} \mathrm{m}^{-1}\right)$. Esses resultados confirmam a influência do tempo de embebição no crescimento das plantas de cajueiro, pois quando a semente é exposta por tempos prolongados ao peroxido de hidrogênio pode ocasionar a ação de estresse oxidativo superiores ao necessário para a indução das respostas antioxidantes das plantas, como a produção de metabolitos secundários, ocasionando danos ao seu desenvolvimento (WOJTYLA et al., 2016).

Conforme o resultado da análise de variância (Tabela 3) houve interação entre os fatores estudados (salinidade da água de rega e concentrações de peróxido de hidrogênio), aos 80 DAE sobre massa seca de raiz, massa seca total e Índice de Qualidade de Dickson (IQD). 


\section{MORFOFISIOLOGIA E QUALIDADE DE PORTA-ENXERTO DE CAJUEIRO SOB PERÓXIDO DE HIDROGÊNIO E ESTRESSE SALINO}

Tabela 3. Análise de variância para massa seca de raiz (MSR), total (MST) e Índice de Qualidade de Dickson (IQD) de porta-enxerto de cajueiro Embrapa 51, provenientes de sementes tratadas com diferentes concentrações de $\mathrm{H}_{2} \mathrm{O}_{2}$ e regados com águas salinas, aos 80 dias após emergência.

\begin{tabular}{lcccc}
\hline \multirow{2}{*}{ Fonte de variação } & \multirow{2}{*}{ GL } & \multicolumn{3}{c}{ Quadrado Médio } \\
\cline { 3 - 5 } & & MSR & MST & IQD \\
\hline Níveis salinos (S) & 4 & $0,94^{* *}$ & $9,03^{* *}$ & $0,23^{* *}$ \\
Reg. Linear & 1 & $3,63^{* *}$ & $33,32^{* *}$ & $0,88^{* *}$ \\
Reg. Quadrática & 1 & $0,04^{* *}$ & $2,69^{* *}$ & $0,03^{* *}$ \\
Peróxido de hidrogénio $\left(\mathrm{H}_{2} \mathrm{O}_{2}\right)$ & 3 & $0,20^{* *}$ & $0,48^{* *}$ & $0,003 \mathrm{~ns}$ \\
$\quad$ Reg. Linear & 1 & $0,05^{* *}$ & $1,35^{* *}$ & $0,0002 \mathrm{~ns}$ \\
Reg. Quadrática & 1 & $0,003 \mathrm{~ns}$ & $0,03 \mathrm{~ns}$ & $0,005 \mathrm{~ns}$ \\
Interação $\left(\mathrm{S} \mathrm{x} \mathrm{H}_{2} \mathrm{O}_{2}\right)$ & 12 & $0,14^{*}$ & $2,18^{* *}$ & $0,03^{*}$ \\
Bloco & 3 & $0,01 \mathrm{~ns}$ & $0,062^{*}$ & $0,004 \mathrm{~ns}$ \\
$\mathrm{CV}(\%)$ & & 6,11 & 3,56 & 8,15 \\
\hline
\end{tabular}

Para a variável MSR as plantas que não receberam peróxido $\left(0 \mu \mathrm{M}\right.$ de $\left.\mathrm{H}_{2} \mathrm{O}_{2}\right)$ tiveram comportamento quadrático onde conforme equação de regressão o valor máximo de $1,09 \mathrm{~g}$ por planta foi obtido na condutividade elétrica de $1,3 \mathrm{dS} \mathrm{m}^{-1}$ (Figura 3A). Porém o aumento das concentrações de peróxido de hidrogénio originou um declínio na produção de massa seca de raiz e conforme equações de regressão (Figura 3A), o uso das concentrações 10, 20 e $30 \mu \mathrm{M}$ de $\mathrm{H}_{2} \mathrm{O}_{2}$ causaram redução linear sobre a MSR com o a elevação da salinidade na água de rega, onde as plantas que foram irrigados com a maior CEa $\left(3,5 \mathrm{dS} \mathrm{m}^{-1}\right)$ apresentaram decréscimos de 0,54 (38,23\%); 1,04 (61,77\%) e $0,63(42,27 \%) \mathrm{g}$ por planta com a utilização de 10,20 e $30 \mu \mathrm{M}$ de $\mathrm{H}_{2} \mathrm{O}_{2}$ quando comparadas com as plantas que receberam a menor

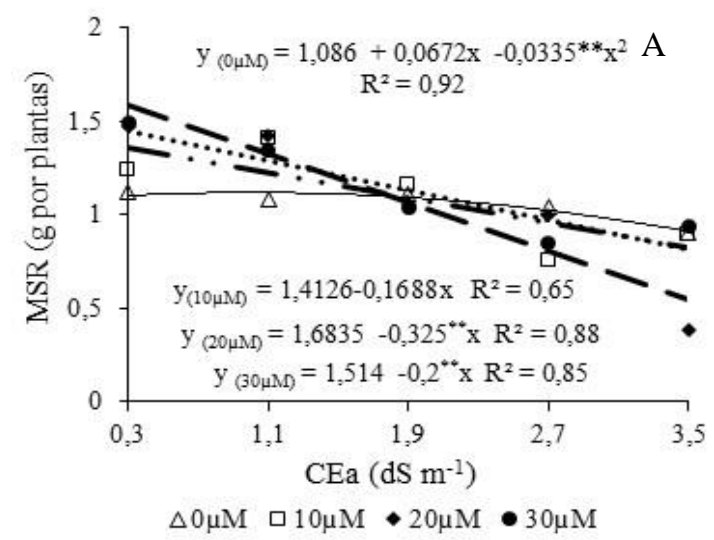

salinidade $\left(0,3 \mathrm{dS} \mathrm{m}{ }^{-1}\right)$. No entanto verifica-se para a MST (Figura 3B) que o melhor ajuste dos dados foi em equação quadrática na utilização da concentração de $20 \mu \mathrm{M} \mathrm{e} \mathrm{H}_{2} \mathrm{O}_{2}$, onde o maior valor da MST foi encontrado sob o nível de CEa de $1,0 \mathrm{dS} \mathrm{m}^{-1}$. Neste contexto, salienta-se que o uso das concentrações de $10 \mathrm{e}$ $30 \mu \mathrm{M}$ de $\mathrm{H}_{2} \mathrm{O}_{2}$, unidos com o efeito do estresse salino na produção de porta enxerto de cajueiro Embrapa 51, causou efeito deletério com reduções de 49,99 e 41,80\% nas plantas regadas com água de $3,5 \mathrm{dS} \mathrm{m}^{-1}$.

Esse estresse causa redução na pressão de turgescência em virtude da diminuição do conteúdo de água, resultando em declínio na expansão da parede celular, menor crescimento e baixa produção de matéria seca (FREIRE et al., 2010).

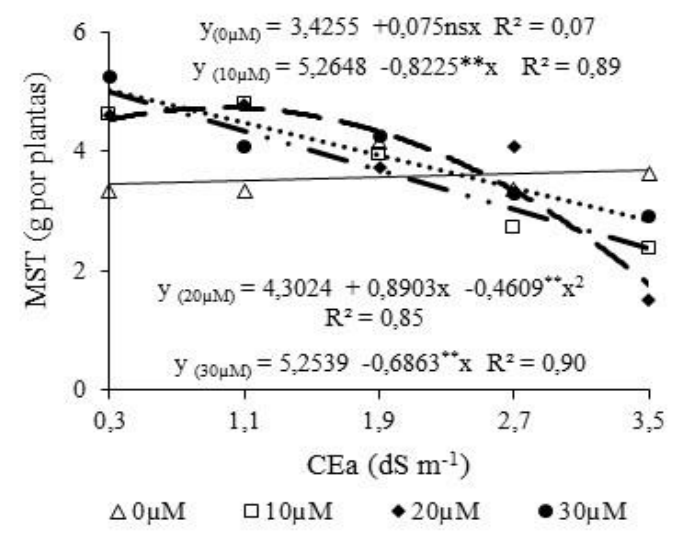

Figura 3. Massa seca de raiz -MSR (A) e massa seca total - MST (B) de porta-enxerto de cajueiro Embrapa 51, em função da interação entre os níveis de salinidade da água - CEa e diferentes concentrações de $\mathrm{H}_{2} \mathrm{O}_{2}$, aos 80 dias após emergência. 
Souza et al.

Analisando o efeito da salinidade no IQD (Figura 4) constata-se que as concentrações de 0 e $20 \mu \mathrm{M} \mathrm{deH}_{2} \mathrm{O}_{2}$ apresentaram resposta quadrática sendo os maiores valores desta variável $(0,60$ e 0,73$)$ obtidos quando se regou as plantas com 1,3 e 0,3 dS $\mathrm{m}^{-1}$, respectivamente. Pesquisas desenvolvidas por Gondim et al. (2010), com plantas de milho provenientes de sementes pré-tratadas com $\mathrm{H}_{2} \mathrm{O}_{2}$, observaram que o pré-tratamento conferiu tolerância à salinidade nas plantas.

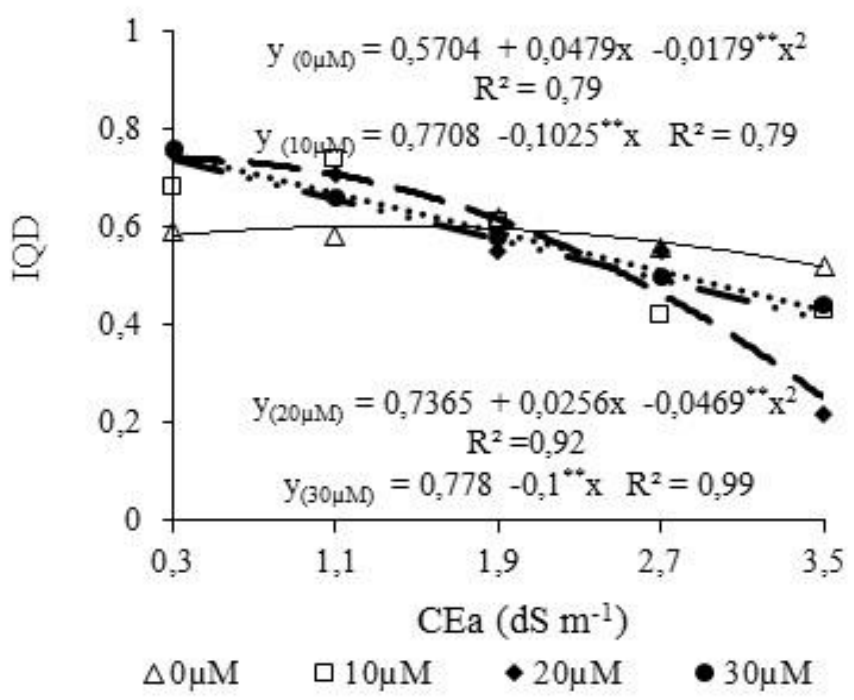

Figura 4. Índice de Qualidade de Dickson (IQD) de porta-enxerto de cajueiro Embrapa 51, em função da interação entre os níveis de salinidade da água - CEa e diferentes concentrações de $\mathrm{H}_{2} \mathrm{O}_{2}$, aos 80 dias após emergência.

No entanto verifica-se conforme as equações de regressão (Figura 4), que o uso das concentrações de 10 e $30 \mu \mathrm{M}$ de $\mathrm{H}_{2} \mathrm{O}_{2}$ sobre o IQD causaram diminuições com a elevação da salinidade da água de rega, onde as plantas submetidas a maior CEa $\left(3,5 \mathrm{dSm}^{-1}\right)$ sofreram reduções de $42,55 \%(0,33)$ e $41,13 \%(0,32)$ com a utilização das respectivas concentrações quando comparadas com as plantas que receberam CEa de $0,3 \mathrm{dS} \mathrm{m}^{-1}$.

Apesar das reduções sofridas com a salinidade, os porta-enxertos de cajueiro Embrapa 51 apresentaram o IQD superior a 0,2 sendo considerados de boa qualidade final para estabelecimento no campo. Desta forma, quanto maior este índice tanto melhor a qualidade da muda final, pois relaciona a robustez e o equilíbrio da distribuição de biomassa (OLIVEIRA et al., 2013; SOUZA et al., 2017).

\section{CONCLUSÃO}

As trocas gasosas, formação de massa fresca e seca e a qualidade de porta-enxerto de cajueiro são reduzidas pelo aumento da salinidade de água - CEa de rega, no entanto a rega com água de $\mathrm{CEa} 1,68 \mathrm{dS} \mathrm{m}^{-1}$, promove reduções aceitáveis de $10 \%$ na morfofisiologia do cajueiro "Embrapa 51".

De forma geral, o uso das concentrações de $20 \mu \mathrm{M}$ de peróxido de hidrogênio proporciona os maiores acúmulos de fitomassa e qualidade dos porta-enxertos de cajueiro

\section{REFERÊNCIAS BIBLIOGRÁFICAS}

ALMEIDA, L. H. F.; CORDEIRO, S. A.; PEREIRA, R. S.; COUTO, L. C.; LACERDA, K. W. de S. Viabilidade econômica da produção de caju (Anacardium occidentale L.). Nativa, v. 5, n. 1, p. 09-15, 2017. DOI: 10.5935/2318-7670.v05n01a02

CARVALHO, F. E. L.; LOBO, A. K. M.; BONIFACIO, A.; MARTINS, M. O.; LIMA NETO, M. C.; SILVEIRA, J. A. G. Aclimatação ao estresse salino em plantas de arroz induzida pelo prétratamento com $\mathrm{H}_{2} \mathrm{O}_{2}$. Revista Brasileira de Engenharia Agrícola e Ambiental, v.15, n.4, p.416-423, 2011. 
CAVALCANTI JÚNIOR, A. T.; CHAVES, J. C. M. Produção de mudas de cajueiro. Embrapa Agroindústria Tropical, v.43, n.3, p. 42, 2001.

CLAESSEN, M. E. C. (org.). Manual de métodos de análise de solo. 2 . ed. rev. atual. Rio de Janeiro: Embrapa-CNPS, 1997. 212p. (Embrapa-CNPS. Documentos, 1).

DICKSON, A.; LEAF, A. L. HOSNER, J. F. Quality appraisal of white spruce and white pine seedling stock in nurseries. The Forest Chronicle, v. 36, n. 1, p. 10-13, 1960.

FERREIRA, D. F. Sisvar: um sistema computacional de análise estatística. Ciência e Agrotecnologia, v. 35, n. 6, p. 1039-1042, 2011.

FREIRE, A. L. DE O.; SARAIVA, V. P.; MIRANDA, J. R. P de. BRUNO, G. B. Crescimento, acúmulo de íons e produção de tomateiro irrigado com água salina. Semina: Ciências Agrárias, v. 31, suplemento 1, p. 1133-1144, 2010.

GONDIM, F. A.; GOMES-FILHO, E.; LACERDA, C. F.; PRISCO, J. T.; AZEVEDO NETO, A. D.; MARQUES, E. C. Pretreatment with $\mathrm{H}_{2} \mathrm{O}_{2}$ in maize seeds: effects on germination and seedling acclimation to salt stress. Brazilian Journal of Plant Physiology, v. 22, n. 02, p. 103-112, 2010.

GONDIM, F. A.; GOMES FILHO, E.; MARQUES, E. C. PRISCO, J. T. Efeitos do $\mathrm{H}_{2} \mathrm{O}_{2}$ no crescimento e acúmulo de solutos em plantas de milho sob estresse salino. Revista Ciência Agronômica, v. 42, n. 2, p. 373-38, 2011.

MEDEIROS, J. F. Qualidade da água de irrigação e evolução da salinidade nas propriedades assistidas pelo "GAT" nos Estado do RN, PB e CE. 1992. 173 f. Dissertação (Mestrado em Engenharia Agrícola) - Programa de Pós-Graduação, Universidade Federal da Paraíba, Campina Grande.
MEDEIROS, P. R.; DUARTE, S. N.; UYEDA, C. A.; SILVA, Ê. F. F.; MEDEIROS, J. F. de. Tolerância da cultura do tomate à salinidade do solo em ambiente protegido. Revista Brasileira de Engenharia Agrícola e Ambiental, v. 16, n. 1, p. 51-55, 2012. dx.doi.org/10.1590/S1415-

43662012000100007

NASCIMENTO, E. S.; CAVALCANTE, L. F.; GONDIM, S.C.; SOUZA, J. T. A.; BEZERRA, F. T. C.; BEZERRA, M. A. F. Formação de mudas de maracujazeiro amarelo irrigadas com águas salinas e biofertilizantes de esterco bovino. Revista Agropecuária Técnica, v. 38, $\begin{array}{lllll}\text { n. } & 1, & \text { p. } & 1-8 & 2017 .\end{array}$ doi.org/10.25066/agrotec.v38i1.28090

NGUYEN, G. N.; HAILSTONES, D. L.; WILKES, M.; SUTTON, B. G. Drought-induced oxidative conditions in rice anthers leading to a programed cell death and pollen abortion. Journal of Agronomy \& Crop Science, v.195, p.157- 164, 2009 . doi.org/10.1111/j.1439037X.2008.00357.x

OLIVEIRA, F. T.; HAFLE, O. M. MENDONÇA, V.; MOREIRA, J. N.; PEREIRA JÚNIOR, E. B. Fontes orgânicas e volume de recipiente no crescimento inicial de porta-enxertos de goiabeira. Revista Verde de Agroecologia e Desenvolvimento Sustentável, v.7, n. 2, p. 97-103, 2013.

RHOADES, J. D.; KANDIAH, A. MASHALI, A. M. Uso de águas salinas para produção agrícola. Campina Grande: UFPB, (Estudos da FAO, Irrigação e Drenagem, 48). 2000. 117 p.

SERRANO, L. A. L.; MELO, D. S.; TANIGUCHI, C. A. K.; VIDAL NETO, F. das C.; CAVALCANTE JÚNIOR, L. F. Porta-enxertos para a produção de mudas de cajueiro. Pesquisa Agropecuária Brasileira, v.48, n.9, p.1237-1245, 2013.

SILVA, E. M da.; LACERDA, F. H. D.; MEDEIROS, A. de S.; SOUZA, L. de P. PEREIRA, F. H. F. Métodos de aplicação de diferentes concentrações de $\mathrm{H}_{2} \mathrm{O}_{2}$ em milho sob 
estresse salino. Revista Verde de Agroecologia e Desenvolvimento sustentável, v. 11, n. 3 p. 01 - 07, 2016. dx.doi.org/10.18378/rvads.v11i3.4343

SOUSA, A. B. O de.; BEZERRA, M. A.; FARIAS, F. C. Germinação e desenvolvimento inicial de clones de cajueiro comum sob irrigação com água salina. Revista Brasileira de Engenharia Agrícola e Ambiental, v. 15, n. 4, p. 390-394, 2011.

SOUZA, L. de P.; NOBRE, R. G.; SILVA, E. M. da; LIMA, G. S. de; PINHEIRO, F. W. A.; ALMEIDA, L. L. de S. Formation of 'Crioula' guava rootstock under saline water irrigation and nitrogen doses. Revista Brasileira de Engenharia Agrícola e Ambiental, v.20, p. 739-745, 2016.
SOUZA, L. de P.; NOBRE, R. G.; SILVA, E. M.; GHEYI, H. R. SOARES, L. A. dos A. Produção de porta-enxerto de goiabeira cultivado com águas de diferentes salinidades e doses de nitrogênio. Revista Ciência Agronômica, v. 48, n. 4, p. 596-604, 2017. DOI: $10.5935 / 1806-6690.20170069$

WAHID, A. BASRA, S. M. A. Pretreatment of seed with $\mathrm{H}_{2} \mathrm{O}_{2}$ improves salt tolerance of wheat seedlings by alleviation of oxidative damage and expression of stress proteins. Journal of Plant Physiology, v. 164, n. 03, p. 283-294, 2007.

WOJTYLA, Ł., LECHOWSKA, K., KUBALA, S., GARNCZARSKA, M. Different modes of hydrogen peroxide action during seed germination. Frontiers in Plant Science, v. 7, p.66, 2016. 